\title{
Fluorescence Recognition of Proteinaceous Binders in Works of Art by a Novel Integrated System of Investigation
}

\author{
IRINA CRINA ANCA SANDU, ${ }^{1 *}$ ANA CECILIA A. ROQUE,${ }^{2}$ PAOLO MATTEINI,${ }^{3}$ STEPHAN SCHÄFER,${ }^{4}$ \\ GIOVANNI AGATI,${ }^{5}$ CATARINA RIBEIRO CORREIA, ${ }^{6}$ AND JOANA FORTIO FERNANDES PACHECO VIANA ${ }^{7}$ \\ ${ }^{1}$ REQUIMTE and Departamento de Conservação e Restauro, Faculdade de Ciências e Tecnologia (FCT), Universidade Nova de Lisboa \\ (UNL), 2829-516, Caparica, Portugal \\ ${ }^{2}$ REQUIMTE, Departamento de Química, Faculdade de Ciências e Tecnologia (FCT), Universidade Nova de Lisboa (UNL), 2829-516, \\ Caparica, Portugal \\ ${ }^{3}$ Institute of Applied Physics "Nello Carrara," CNR, Via Madonna del Piano 10, 50019 Sesto Fiorentino, Italy \\ ${ }^{4}$ Departamento de Conservação e Restauro, Faculdade de Ciências e Tecnologia (FCT), Universidade Nova de Lisboa (UNL), 2829-516, \\ Caparica, Portugal \\ 5Institute of Applied Physics "Nello Carrara," CNR, Via Madonna del Piano 10, 50019 Sesto Fiorentino, Italy \\ ${ }^{6}$ Faculdade de Ciências e Tecnologia (FCT), Universidade Nova de Lisboa (UNL), 2829-516, Caparica, Portugal \\ ${ }^{7}$ Faculdade de Ciências e Tecnologia (FCT), Universidade Nova de Lisboa (UNL), 2829-516, Caparica, Portugal
}

\begin{abstract}
KEY WORDS fluorescence microscopy/stain; microspectrofluorometry; protein-based binder;
\end{abstract} cross-section

\begin{abstract}
Fluorescence microscopy and microspectrofluorometry are important tools in the characterization and identification of proteins, offering a great range of applications in conservation science. Because of their high selectivity and sensitivity, the combination of these techniques can be exploited for improved recognition and quantification of proteinaceous binders in paintings and polychromed works of art. The present article explores an analytical protocol integrating fluorescence microscopy and fluorometry for both identification and mapping of proteinaceous binders (in particular egg and glues) in paint samples. The study has been carried out on historically accurate reconstructions simulating the structure and composition of tempera and oil paints containing these binders. To assess the spatial distribution of specific proteins within the paint layers, cross-sections from the reconstructions were analyzed by fluorescence imaging after staining with an exogenous fluorophore. Reference fluorescence spectra for each layer were acquired by a multichannel spectral analyzer and compared after Gaussian deconvolution. The results obtained demonstrated the effectiveness of the integrated protocol, highlighting the potential for the use of fluorescent staining coupled with microspectrofluorometry as a routine diagnostic tool in conservation science. The current work creates a set of fully characterized reference samples for further comparison with those from actual works of art. Microsc. Res. Tech. 00:000-000, 2011. @ 2011 Wiley-Liss, Inc.
\end{abstract}

\section{INTRODUCTION}

Many analytical methods for the characterization of binding media (AA.VV, 2009; Mills and White, 1994; Rinuy and Gros, 1989) in polychrome works of art were developed during the past 20 years, with biochemical techniques (Cartechini et al., 2010; Dolci et al., 2008; Doménech-Carbó, 2008; Leo et al., 2009; Sandu et al., 2009) offering a useful complement to classical techniques (AA.VV, 2009; Dolci et al., 2008; Sandu et al., 2009; White, 1984) such as spectroscopy/mass spectrometry, chromatography, micro-beam, and thermoanalytical methods. Biochemical techniques, mainly from the field of proteomics, have been proven particularly effective for the identification of proteins, and in particular the application of fluorescent stains (AA.VV., 1962; Banks and Paquette, 1995; Holmes and Lantz, 2001; James and Tas, 1984; Maeda et al., 1969; Wang et al., 2006) to cross-sections of paint fragments (Doménech-Carbó, 2008; Gay, 1976; Leo et al., 2009; Messinger, 1992; Plesters, 1956; Schaefer, 1997; Wolbers 1990, 2000; Wolbers and Landrey, 1987).

The use of fluorescent stains has been reported for medium analysis on paint sample cross-sections, as an alternative to visible stains such as Amido Black, Acid
Fuchsine, Ponceau S, Stain-all (Gay, 1976; Messinger, 1992; Mills and White, 1994; Plesters, 1956; Rinuy and Gros, 1989; White, 1984). This approach was initially popularized by Richard Wolbers in conjunction with new cleaning methods, as an aid to the choice of cleaning system and for characterization of binding media in cross-sections of paint layers (Wolbers 1990, 2000; Wolbers and Landrey, 1987). Besides FITC and Rhodamine, which are popular alternatives to traditional visible dyes, other fluorophores, mainly used for biological labelling (AA.VV., 1962; Banks and Paquette, 1995; Holmes and Lantz, 2001; James and Tas, 1984; Maeda et al., 1969; Wang et al, 2006), have been recently explored (Sandu et al., 2009; Schaefer, 1997).

In the conservation field, fluorescence microscopy has been mainly applied in two ways: by investigating

\footnotetext{
*Correspondence to: Irina Crina Anca Sandu, REQUIMTE and Departamento de Conservação e Restauro, Faculdade de Ciências e Tecnologia (FCT), Universidade Nova de Lisboa (UNL), 2829-516, Caparica, Portugal. E-mail: irina.sandu@ dq.fct.unl.pt

Received 7 January 2011; accepted in revised form 12 June 2011

Contract grant sponsor: Foundation for Science and Technology (FCT), Portugal. DOI 10.1002/jemt.21060

Published online in Wiley Online Library (wileyonlinelibrary.com).
} 
naturally fluorescent materials (Dolci et al., 2008; Gay, 1976; Messinger, 1992; Plesters, 1956; Rinuy and Gros, 1989; White, 1984), and by staining specimens with a fluorescent dye (Sandu et al., 2009; Schaefer, 1997; Wolbers, 1999, 2000; Wolbers and Landrey, 1987). The microscope observation of the intrinsic fluorescence (auto-fluorescence) originated by the fluorophores contained within the paint binding material is useful in the routine examination of artifacts (Karpowicz, 1981; Messinger, 1992; Plesters, 1956). In particular, protein fluorescence is generally excited by using UV wavelengths ranging from 280 to $365 \mathrm{~nm}$. Most of the emissions are due to excitation of tryptophan residues, with a lower contribution from tyrosine and phenylalanine. Additional fluorescence is developed after amino-acid degradation by age-related cross-linkage and Maillard reaction products (Deyl et al., 1999). Another strategy consists of labeling proteins with various exogenous fluorophores, thus producing fluorescent conjugates, or "tags" (James and Tas, 1984; Mills and White, 1994; Wang et al., 2006). The emission from the tagged protein is called extrinsic fluorescence. Tagging a protein with fluorescent labels is an important and valuable tool for studying structure, microenvironment, and distribution of the protein in a complex matrix (such as a paint composite, which includes preparation layers, paint, and surface coatings) (AA.VV., 1962; Maeda et al., 1969). Compared to visible stains, the extrinsic fluorescence approach has some distinct advantages: exogenous fluorophores can be detected at a much lower concentration as they are reported to be $\sim 100$ times more sensitive (AA.VV., 1962), they can be delivered in organic solvent thereby avoiding aqueous dissolution of the proteins (Wolbers and Landrey, 1987), and finally, the color of the paint film does not interfere with their visibility (Rinuy and Gros, 1989).

The possibility of extracting within microscopic samples the spectral characteristics of painting materials (Matteini et al., 2009; Nevin et al., 2007) makes fluorescence spectroscopy a promising tool for coupling the sensitivity of fluorescence measurements with the spatial resolution of a microscope (Bottiroli et al., 1984, 2005).

However, despite advanced research in this field, a systematic investigation of fluorescence properties of complex mixtures of proteins and/or other organic materials (such as oils, resins, starch) found both within and on the surface of works of art is still lacking. In addition, the study of the fluorescence behavior of these materials can now be conveniently integrated with imaging techniques and spatially resolved analytical methodologies that can be exploited for highly specific identification of the organic constituents.

This article reports on the investigation of a novel approach for the recognition and mapping of proteinaceous binders integrating the potential of two complementary techniques: fluorescence imaging and microspectrofluorometry. This work has been carried out on historically accurate reconstructions which simulate the structure and composition of tempera and oil paints containing egg and glues. Fluorescence imaging revealed the spatial distribution of proteins within the paint layers of cross-sectioned samples upon staining with a suitable exogenous fluorophore. The fluorescence signal of the single layers was then characterized by microspectrofluorometry. The current work describes the successful application of the protocol on reference samples to be further used for comparative studies with samples from actual works of art.

\section{MATERIALS AND METHODS Tempera Reconstructions}

Whole egg, egg white, and egg yolk are the main binders used in tempera paints and in some cases form mono-component layers (i.e., temporary varnishes made of egg white). Ovalbumin is the most abundant protein found in egg white, while phosvitin is the specific protein from the egg yolk (Masschelein Kleiner, 1992; Phenix, 1996). Animal glues, mainly composed of collagen from the bones, tendons, cartilage, and skin of animals (Florian, 2007; Gettens and Stout, 1966; Masschelein Kleiner, 1992), have been in use since ancient times for sizing panel and canvas paintings or as binders in ground and paint layers. Fish glue (isinglass), obtained from the swim bladders of sturgeons (Sandu et al., 2005), has also been used as a consolidant in conservation treatments and is listed as material used in some "temporary" varnishes (Carlyle, 2001).

\section{Oil Painting Reconstructions}

Few samples from historically accurate reconstructions of oil paint were kindly provided by Professor Leslie Carlyle (Department of Conservation of NOVA University, Lisbon), being extensively described in the final HART report hosted at the ICN in Amsterdam (Carlyle L. 2005).

\section{Materials}

Chicken eggs (biological source) were employed together with isinglass (sturgeon bladder) and animal glues (rabbit skin glue and bovine skin glue) purchased from Cleton and Lefranc et Buorgeois in France; Kremer Pigmente and Cornelissen in Germany). These raw materials were used to prepare aqueous solutions of different concentrations (from 5 to $15 \%$ ) which were successively applied as intermediate layers over tempera ground reconstructions or in the ground preparations (mixed with chalk or gypsum).

\section{Preparation}

Tempera painting reconstructions (mock-up samples) were prepared according to four recipes (summarized in Table 1). Layers typically included the substrate (wood or canvas); the preparation layers: size layer (a sealing layer to isolate the substrate) consisting of animal glue, and the ground layer (filler plus binder to prepare the surface for subsequent paint); one or several colored layers made of pigments bound with egg (whole, white, yolk) or animal glues. The filler used in the ground layer/s was gesso (Gy) and calcium carbonate (CC), respectively. The following pigments were used in the paint layers: red/yellow ochres $(\mathrm{R} / \mathrm{YO})$, burnt umber (BU), terra verde (T); lead white (LW), zinc white $(\mathrm{ZW})$, vermillion $(\mathrm{V})$, and alizarin $(\mathrm{Al})$. Pigments were purchased from Zecchi, CTS, and Ferrario Color (Italy), Kremer Pigmente and Cornelissen (Germany).

The criteria for the creation of the tempera reconstructions were based on the expected outcome of the 
integrated protocol because the staining together with the microspectrofluorimetric detection should:

a. recognize and map the presence of the glues (animal and fish) where they are present as sizing and intermediate layers between the ground and the paint layers;

b. verify the influence or possible interference of the filler in the ground (both gesso and chalk were used, with different glues) and/or of the pigment (natural, synthetic, non-fluorescent, fluorescent) in the char-

TABLE 1. Tempera paint recipes ${ }^{a}$ used in the reconstructions

\begin{tabular}{ll}
\hline Code & \multicolumn{1}{c}{ Ingredients } \\
\hline T(EG) = whole egg & 10 parts (V/V) whole egg \\
tempera & 5 parts (V/V) linseed oil \\
& 10 parts (V/V) water \\
& A few drops of white vinegar \\
T(EY) = egg yolk & 15 mL egg yolk without skin \\
tempera & 5 mL distilled water \\
& 5 drops of white vinegar \\
TG = tempera & 3 parts (V/V) egg yolk \\
grassa & 1 part (V/V) water \\
& 1.5 parts (V/V) nut or poppy seed oil \\
& A few drops of white vinegar \\
& 1 part (V/V) Gum Arabic (water solution 1:5 \\
(w/w)) \\
EW = egg white & Egg white separated from yolk and beaten \\
tempera & Let stand over night and separate the foam \\
& before use
\end{tabular}

${ }^{\text {a}}$ Recipe sources: TEG - B. Slansky (Slansky, 1956), TG-traditional recipe (personal communication, Petr. F.), EW and TE(Y)—adapted from Ceninno Cennini's treatise (Cennini, 1984). acterization of the proteinaceous binder in each paint layer;

c. differentiate between glue and egg proteins in overlapped layers of paint.

As the fluorescent staining was performed with a stain specific to proteinaceous materials only, it was not possible in this stage of the research to identify and discuss interference caused by non-proteinaceous materials (such as oils or gums) present in the samples (Table 1).

\section{Preparation of the Cross-Sections}

Sixteen samples from both tempera and oil painting reconstructions (on canvas and wooden panel, naturally aged from 6 months to 5 years) were selected for the preparation of cross-sections using both acrylic (Technovit, code A) and polyester (Mecaprex SS with hardener, code $\mathrm{P}$ ) resins (Table 2 ). Ten cross-sections from the sixteen are illustrated in the figures given in the text.

Cross-sections were dry polished with successively finer grades of Micro-mesh abrasive cloths (600, 800, 1,200 , and 4,000 mesh). A felt was used for the final polishing. Water or other aqueous-based liquids are not used during polishing since they could dissolve the proteinaceous component in the samples.

\section{ANALYTICAL PROTOCOL}

An integrated approach for the analysis of proteinbased binders in paintings and polychromes results in

TABLE 2. Cross-sections obtained from tempera and other paint reconstructions (all samples marked with an asterisk are from the HART project $^{a}$ ), with the indication of the embedding resin

\begin{tabular}{|c|c|c|}
\hline $\begin{array}{l}\text { Cross-section } \\
\text { number and } \\
\text { embedding } \\
\text { resin code }\end{array}$ & $\begin{array}{l}\text { Sample } \\
\text { original } \\
\text { code }\end{array}$ & Layered structure and composition (described from the upper layer to the bottom layer) \\
\hline $1(\mathrm{P})$ & F2_2* & $\begin{array}{l}\text { Oil paint layer (lead white in lead treated linseed oil) applied over fluid application of } 7 \% \text { animal glue } \\
\text { from modern alum-tawed goat leather (CG) over a ground of chalk + glue, applied on linen canvas } \\
\text { sized with the same glue used in the ground ( } 7 \% \text { traditional alum-tawed goat leather, HG). }\end{array}$ \\
\hline $2(\mathrm{P})$ & G2.3.2C_1* & Egg white (EW) over ground: lead white + chalk $(50 \%)+$ lead treated linseed oil on polyester film \\
\hline $3(\mathrm{P})$ & G2.3.2C_2* & Oil paint layer (lead white in lead treated poppy oil) over G2.3.2C_1 above \\
\hline $4(\mathrm{P})$ & LB EX10* & $\begin{array}{l}\text { Ground (chalk }+7 \% \text { glue, HG) over canvas sized with the same glue used in the ground (size glue } \\
\text { applied as a gel over a linen canvas) }\end{array}$ \\
\hline $5(\mathrm{P})$ & $\mathrm{J} 2 \mathrm{~b}$ & $\begin{array}{l}\text { Ground (gesso }+10 \% \text { rabbit skin glue) over a } 6 \% \text { rabbit skin glue size applied on another ground (chalk } \\
+15 \% \text { rabbit skin glue) on a wooden support }\end{array}$ \\
\hline $6(\mathrm{P})$ & J3a_T & $\begin{array}{l}\text { Layer of tempera grassa (TG) with Terra verde over a } 6 \% \text { rabbit skin glue layer applied on a ground } \\
\text { (chalk }+15 \% \text { rabbit skin glue) on a wooden support. }\end{array}$ \\
\hline $7(\mathrm{P})$ & J3a_BU & $\begin{array}{l}\text { Layer of tempera grassa (TG) and Burnt Umber over a } 6 \% \text { rabbit skin glue layer applied on a ground: } \\
\text { (chalk }+15 \% \text { rabbit skin glue) on a wooden support. }\end{array}$ \\
\hline $8(\mathrm{P})$ & J13_Al & $\begin{array}{l}\text { Layer of tempera grassa (TG) and Alizarin over a 15\% fish glue layer applied on a ground (gesso }+15 \% \\
\text { rabbit skin glue) on a wooden support. }\end{array}$ \\
\hline $9(\mathrm{~A})$ & J15_Al & $\begin{array}{l}\text { Layer of whole egg tempera (TEG) and Alizarin over a } 10 \% \text { rabbit skin glue layer applied on a ground } \\
\text { (gesso }+15 \% \text { rabbit skin glue) on a } 15 \% \text { rabbit skin glue sized wooden support. }\end{array}$ \\
\hline $10(\mathrm{P}$ and $\mathrm{A})$ & J16_BU & $\begin{array}{l}\text { Layer of whole egg tempera (TEG) and Burn Umber over a } 6 \% \text { fish glue layer applied on a ground (gesso } \\
\quad+10 \% \text { fish glue) on a wooden support. }\end{array}$ \\
\hline $11(\mathrm{P})$ & C3_YO & $\begin{array}{l}\text { Layer of whole egg (EG) and Yellow ochre applied over a ground (gesso }+10 \% \text { rabbit skin glue) on a } \\
\text { wooden support. }\end{array}$ \\
\hline $12(\mathrm{P})$ & C4_V & $\begin{array}{l}\text { Layer of whole egg (EG) and Vermillion over a ground (gesso }+10 \% \text { rabbit skin glue) on a wooden } \\
\text { support. }\end{array}$ \\
\hline $13(\mathrm{~A})$ & C19_LW & $\begin{array}{l}\text { Layer of egg yolk (EY) and Lead white over a ground (gesso }+10 \% \text { rabbit skin glue) on a wooden } \\
\text { support. }\end{array}$ \\
\hline $14(\mathrm{P})$ & C41_T & $\begin{array}{l}\text { Layer of whole egg tempera (TEG) and Terra verde over a } 6 \% \text { fish glue sized ground (gesso }+10 \% \text { rabbit } \\
\text { skin glue) on a wooden support. }\end{array}$ \\
\hline $15(\mathrm{P})$ & C41_BU & $\begin{array}{l}\text { Layer of whole egg tempera (TEG) and Burnt umber over a } 6 \% \text { fish glue sized ground (gesso }+10 \% \\
\text { rabbit skin glue) on a wooden support. }\end{array}$ \\
\hline $16(\mathrm{P})$ & C41_ZW & $\begin{array}{l}\text { Layer of whole egg tempera (TEG) and Zinc white over a } 6 \% \text { fish glue sized ground (gesso }+10 \% \text { rabbit } \\
\text { skin glue) on a wooden support. }\end{array}$ \\
\hline
\end{tabular}

$\mathrm{P}$ - polyester resin; A-acrylic resin.

${ }^{a}$ HART project Report 2005, unpublished, copy available from L. Carlyle. 
TABLE 3. Integrated area and amplitude contributions of deconvolution bands obtained by Gaussian curve-fitting analysis of the fluorescence spectra of nine sample layers stained with Sypro Ruby

\begin{tabular}{|c|c|c|c|c|c|c|c|}
\hline \multirow{2}{*}{$\begin{array}{l}\text { Stained } \\
\text { layer ID }\end{array}$} & \multirow[b]{2}{*}{ Sample ID } & \multicolumn{3}{|c|}{ Integrated area } & \multicolumn{3}{|c|}{ Amplitude } \\
\hline & & $A 1$ & $A 2$ & A3 & $I 1$ & $I 2$ & $I 3$ \\
\hline 1 & G2.3. 2C_1 (p) & $74 \pm 1$ & $28 \pm 1$ & $7 \pm 1$ & $0.93 \pm 0.03$ & $0.36 \pm 0.04$ & $0.08 \pm 0.01$ \\
\hline 2 & LB EX10 (s) & $77 \pm 3$ & $39 \pm 2$ & $11 \pm 1$ & $0.90 \pm 0.04$ & $0.45 \pm 0.03$ & $0.13 \pm 0.02$ \\
\hline 3 & $\mathrm{~J} 2 \mathrm{~b}(\mathrm{~g})$ & $76 \pm 3$ & $36 \pm 1$ & $10 \pm 1$ & $0.88 \pm 0.01$ & $0.44 \pm 0.02$ & $0.10 \pm 0.02$ \\
\hline 4 & C3_YO (p) & $77 \pm 4$ & $26 \pm 1$ & $6 \pm 1$ & $0.95 \pm 0.02$ & $0.32 \pm 0.01$ & $0.08 \pm 0.01$ \\
\hline 5 & C3_YO (g) & $73 \pm 3$ & $37 \pm 2$ & $11 \pm 1$ & $0.93 \pm 0.01$ & $0.47 \pm 0.02$ & $0.14 \pm 0.01$ \\
\hline 6 & J13_Al (p) & $77 \pm 1$ & $29 \pm 1$ & $10 \pm 1$ & $0.90 \pm 0.05$ & $0.35 \pm 0.03$ & $0.11 \pm 0.02$ \\
\hline 7 & J13_Al (g) & $76 \pm 3$ & $42 \pm 2$ & $13 \pm 1$ & $0.84 \pm 0.01$ & $0.48 \pm 0.02$ & $0.15 \pm 0.01$ \\
\hline 8 & J16_BU (p) & $78 \pm 3$ & $31 \pm 1$ & $8 \pm 1$ & $0.93 \pm 0.02$ & $0.38 \pm 0.03$ & $0.09 \pm 0.01$ \\
\hline 9 & J16_BU (g) & $78 \pm 3$ & $40 \pm 2$ & $15 \pm 2$ & $0.96 \pm 0.02$ & $0.51 \pm 0.01$ & $0.17 \pm 0.01$ \\
\hline
\end{tabular}

$\mathrm{p}=$ pigment layer; $\mathrm{g}=$ ground layer; $\mathrm{s}=$ size layer. Data are expressed as average value $\pm \mathrm{SD}$.

as much information as possible being extracted, thereby making the best use of each sample (Piqué, 2006). A complete protocol of investigation of organic binders in a micrometric sample involve the following steps: (1) detection of organic material (proteinaceous, lipid or polysaccharide-based, or complex mixtures, as in the case of egg temperas); (2) characterization of the class of organic materials (proteins, lipids, polysaccharides etc.); (3) characterization of the type of organic material (for proteins: animal glue, casein, egg-yolk or white); (4) discrimination between different biological sources of binders (i.e., a rabbit glue versus a fish glue); (5) discrimination among organic binders in mixtures (ratios between various binders: egg and glue, glue and casein etc.).

This article discusses two complementary analytical techniques for discriminating and mapping proteinaceous binders consisting of egg and glues.

\section{Optical Microscopy (OM) and Staining Test}

Microscope images were taken from the cross-sections at different magnifications (from $50 \times$ to $500 \times$ ) using an Axioplan Zeiss 2 imaging binocular microscope, coupled to a Nikon DXM1200F digital camera. The filter blocks used for observing the fluorescence were filter 8 (G 365, FT 395, and LP 420) and filter 6 (BP 450-490, FT 510, and LP 515). Visual light observations (illumination position for dark field observation, abbreviated as f2) were performed in reflection geometry.

A biomedical non-covalent stain $\left(\right.$ Sypro Ruby ${ }^{1}$ ) commercialized by Molecular Probes (USA) was used for fluorescence microscopy measurements. This fluorescent stain is used in the proteomics field (adopted from $1 \mathrm{D}$ and 2D gel electrophoresis) and has several advantages: nanogram sensitivity, high selectivity, lower detection limits than other stains (e.g., silver staining), a straightforward staining procedure (fixation followed by incubation, without any washing), and it is available as a ready-to-use solution (one drop is applied directly on the cross-section surface using a Pasteur pipette).

${ }^{1}$ The stain was selected, tested and proposed for paint cross sections as part of doctoral research, "Microscopic Fluorescence Staining Techniques for the Identification of Proteinaceous Binding Media within Paint Cross Sections", in progress, Stephan Schäfer.

\section{Microspectrofluorometry}

Microspectrofluorometric measurements were performed with an inverted epifluorescence microscope (Diaphot, Nikon, Japan) equipped with a high-pressure mercury lamp light source (HBO 100W; Osram, Augsberg, Germany). The excitation wavelength at $488 \mathrm{~nm}$ was selected by using a $10-\mathrm{nm}$ bandwidth interference filter, 488FS10-25 (Andover Corporation, Salem, NH) coupled with a DM510 (Nikon) dichroic mirror. Fluorescence spectra were recorded with a $100 \times$ Plan Fluor (Nikon) objective and acquired with a CCD multichannel spectral analyzer (PMA 11-C5966; Hamamatsu, Photonics Italia, Arese, Italy) connected to the microscope through a 1-mm-core fibre bundle.

Cross-sections stained with Sypro Ruby dye were analyzed along with corresponding control samples which had not been stained. The fluorescence signal from an $80 \mu^{2}$ spot was integrated over a 3 -s period. Residual excitation light was removed by an OG515 long-pass filter (Schott Glass, Mainz, Germany). The fluorescence spectra were normalized to the peak intensity, corrected for the transmission properties of both optics and the autofluorescence contribution, and finally smoothed. Curve fitting was performed using the Gaussian deconvolution algorithm from Peak Fit software (v 4.00, Jandel Scientific, Corde, Madera, CA). A linear combination of three Gaussian bands with shared full width at half-maximum (FWHM) was employed. The relative area and intensity contributions of the single bands were calculated using the integral and the amplitude of the band areas derived from the Gaussian spectra deconvolution. Average values $( \pm \mathrm{SD})$ of six replicas are tabulated in Table 3 .

\section{RESULTS AND DISCUSSION}

A simplified protocol is proposed for egg and glue binders, to be applied to samples from paintings and polychromes (Fig. 1):

a. The optical microscopy examination of samples' cross-sections has been performed before and after staining with the fluorescent dye to establish the presence of the proteinaceous material, alone or in mixtures with other non-proteinaceous binders;

b. Layer by layer acquisition of fluorescence spectra (within the paint composite) has been performed to establish the type of proteinaceous binder (glue vs. egg protein). 


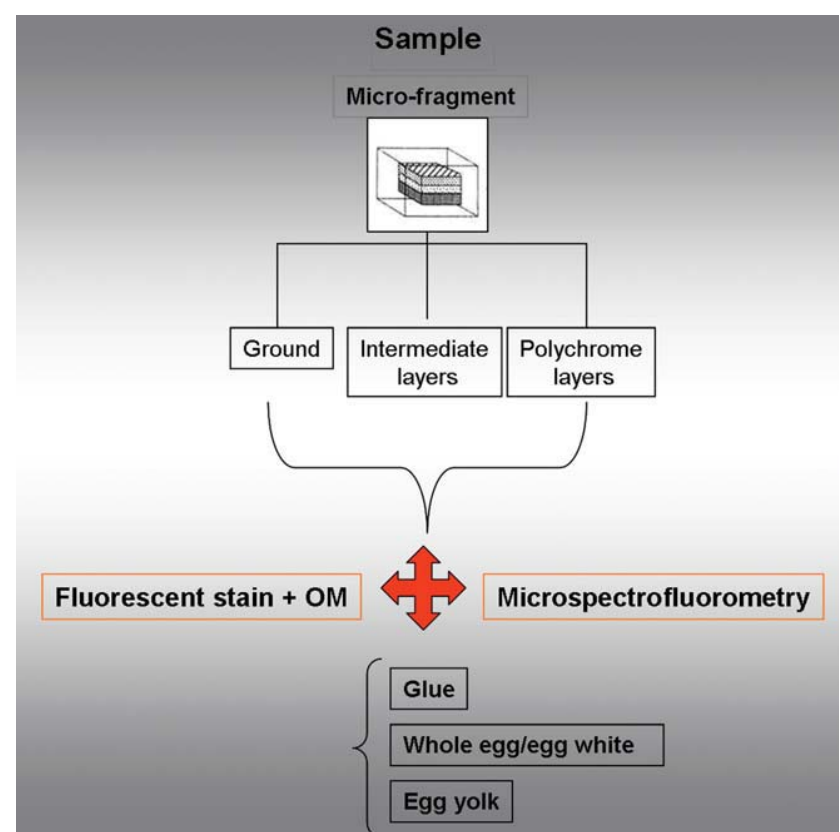

Fig. 1. General scheme of the analytical protocol. [Color figure can be viewed in the online issue, which is available at wileyonlinelibrary. com.]

\section{Fluorescence Imaging and Mapping}

Initially, unstained cross-sections were checked for auto-fluorescence, which may arise from both the sample components as well as from the embedding media. No significant differences in the fluorescence from different embedding media were detected, nor from sample components.

The use of stains is particularly effective for discriminating overlapping layers of different proteinaceous materials, such as fish (CP) or animal glue (CA). The size layers over canvas or wooden supports are clearly visible in cross sections of samples after fluorescent staining but it is not possible to distinguish the source (e.g., goat or rabbit skin glue) with simple OM. Figure 2 shows cross-sections of four samples: two from HART project (Carlyle, 2005), 1 and 3; and two samples of green earth pigment $(\mathrm{T})$ made according different tempera recipes, 6 (TG-tempera grassa) and 14 (TEGwhole egg tempera), observed under visible light (f2) and green excitation light (f6), before and after staining. The different layers of material in the paint structure are clearly visible upon fluorescence staining: cross-section (1) alum-tawed goat skin glue (HG is traditional preparation and CG is a modern preparation), applied as a gel (HG) over the canvas and as a separate layer applied fluid (CG) between the ground and a top

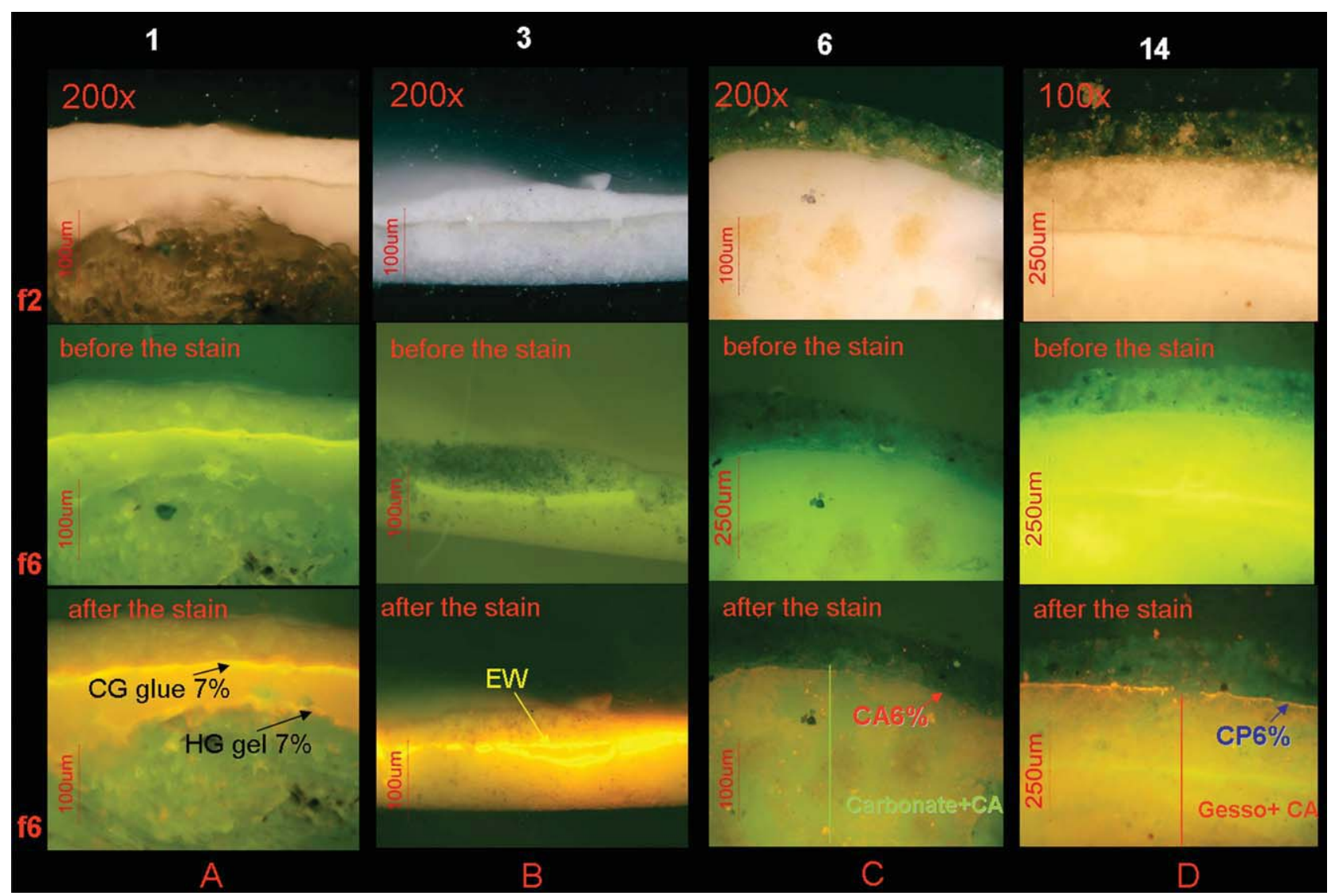

Fig. 2. Visible (f2) and fluorescence (f6) images of layers of egg white, animal and fish glues. (A) cross-section 1 with alum-tawed goat skin glue (CG and $\mathrm{HG}$ ) at $7 \%$; (B) cross-section 3 with egg white (EW) layer; (C) cross-section 6 with animal glue (CA) in the ground and over it; (D) cross-section 14 with animal glue (CA) in the ground and fish glue (CP) on top of the ground. [Color figure can be viewed in the online issue, which is available at wileyonlinelibrary.com.] 
layer of lead white oil paint; cross-section (3) egg white (EW) with a strong yellow fluorescence applied between the ground and the top layer of oil paint; cross-section (6) a 6\% rabbit skin glue (CA) as the binder in the ground; cross-section (14) a $6 \%$ fish glue (CP) applied over the ground layers. The fillers from the ground (carbonate in cross-section 6 and gypsum in cross-section 14) have no influence on the overall fluorescence as they are not naturally fluorescent themselves. Note that the fluorescence visible in all four cross-sections in Figure 2 is similar even though the proteinaceous materials are different. It was also not possible to distinguish differences in fluorescence of the stained egg tempera layers; although they have a different composition in egg proteins (the first one contains only egg yolk, while the second has both yolk and egg white).

The distribution of the fluorescent signal from the stain is variable among different cross-sections and is sometime not uniform within the same layer, possibly due to the different consistency and granulometry of the material (i.e., calcium carbonate vs. gypsum in cross-sections 6 and 14, Figs. 2C and 2D). Other variables include sample preparation (i.e., embedding medium) as well as variations in the characteristics of the materials within the layers (surface roughness and composition including granulometry and porosity of the paint and ground materials).

Fluorescent staining proved highly effective for locating a layer of glue in a cross-section where it sits between the ground and the tempera paint layer (Fig. 3). In case of cross-section 7 (Fig. 3A) chalk (CC) and animal glue (CA) were used in the ground, with the CA being also applied as an intermediate layer between the ground and the paint layer. In the case of cross-section 15 (Fig. 3B), gesso (Gy) was mixed with animal glue $(\mathrm{CA})$ in the ground, while fish glue (CP) was used as the intermediate layer.

The fluorescent Sypro Ruby stain was effective in locating the proteinaceous binders even where the binder was mixed with fillers (from grounds) or pigments (from coloured tempera). For example, in the case of white pigments (i.e., lead white, Fig. 4A), the pigments' fluorescent emission does not appear to interfere with the stain's fluorescence nor is here interference with dark and/or colored pigments (such as Burnt umber-Fig. 3). In the case of vermillion, the orange-red color of the fluorescent stain is clearly visible and can be distinguished from the red of the pigment (Fig. 4B). However, some interference is seen when using synthetic auto-fluorescent pigments, such as alizarin (Fig. 4A), as the bright orange color of the stain can overlap with the red color of the organic colorant. Further investigation on other fluorescent colorants used in painting (eosin, madder lake, etc.) should be performed.

Samples from real works of art can introduce limitations for the interpretation of fluorescence images due to the ageing and complex nature of the matrix. Further investigation on aged samples with a wider range of fillers and colorants is anticipated. In addition, the influence of restoration interventions resulting in the addition of new materials to an original composition (i.e., glues/resins in case of facing and consolidation) must be considered.
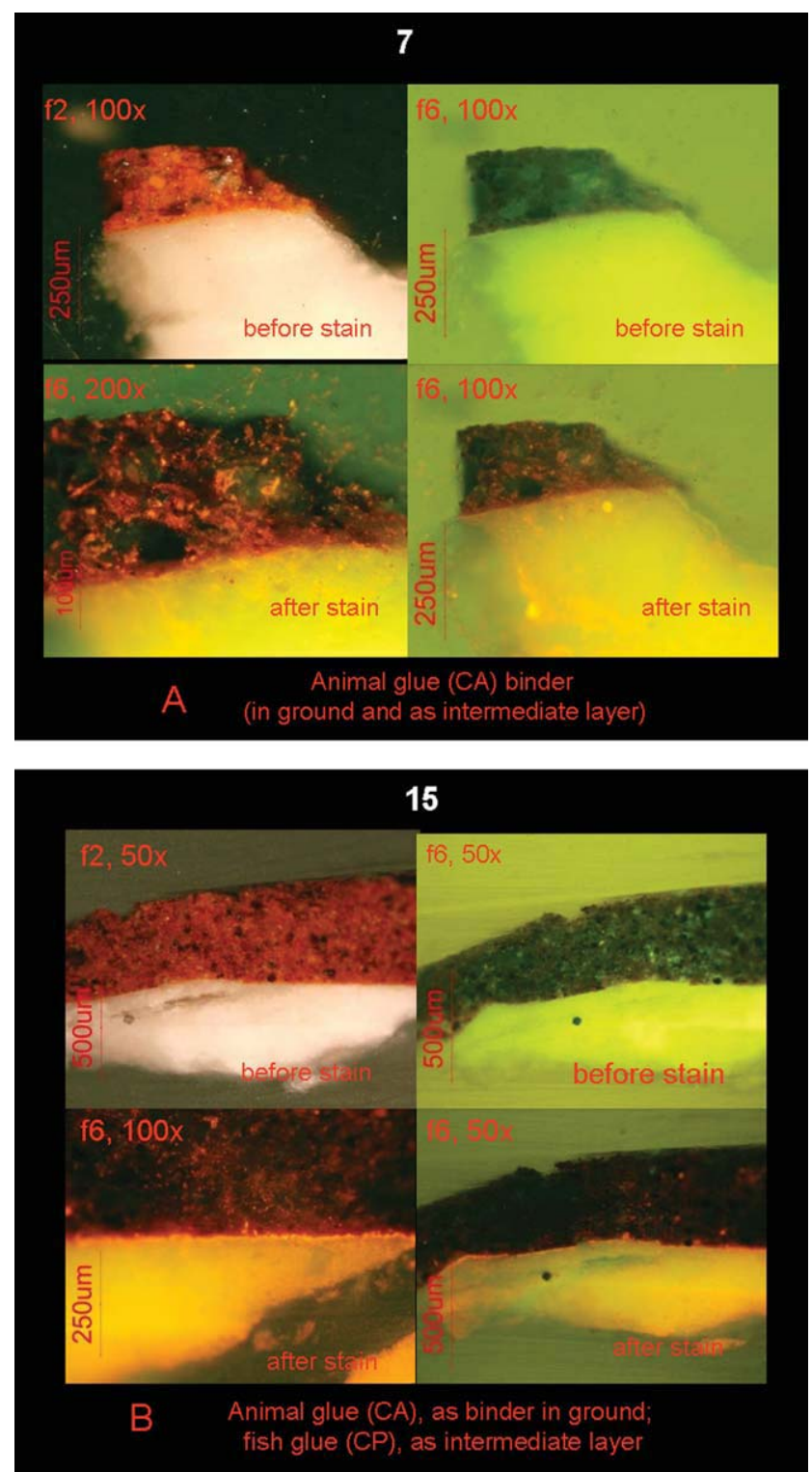

Fig. 3. Visible (f2) and fluorescent (f6) images of grounds and animal glue layers of different composition in two cross-sections: (A) $7-$ tempera grassa based on egg yolk and other non-proteinaceous components (TG) with Burnt umber (BU); (B) 15-whole egg tempera (TEG) with Burnt umber (BU). [Color figure can be viewed in the online issue, which is available at wileyonlinelibrary.com.]

\section{Microspectrofluorometry}

Fluorescence spectra of six cross-sections selected from the sixteenth and stained with Sypro Ruby (Table 3 ) were acquired for each layer, from the ground to the upper colored layers.

The spectra were acquired by selecting a blue (488 $\mathrm{nm}$ ) light for the excitation wavelength to minimize as much as possible spectral artifacts due to fluorescence contributions from the binders (Bottiroli et al., 1984, 2005; Matteini et al., 2009; Nevin et al., 2007) and pigments (Rinuy and Gros, 1989; White, 1984). The spectra were normalized to their maximal intensity to 

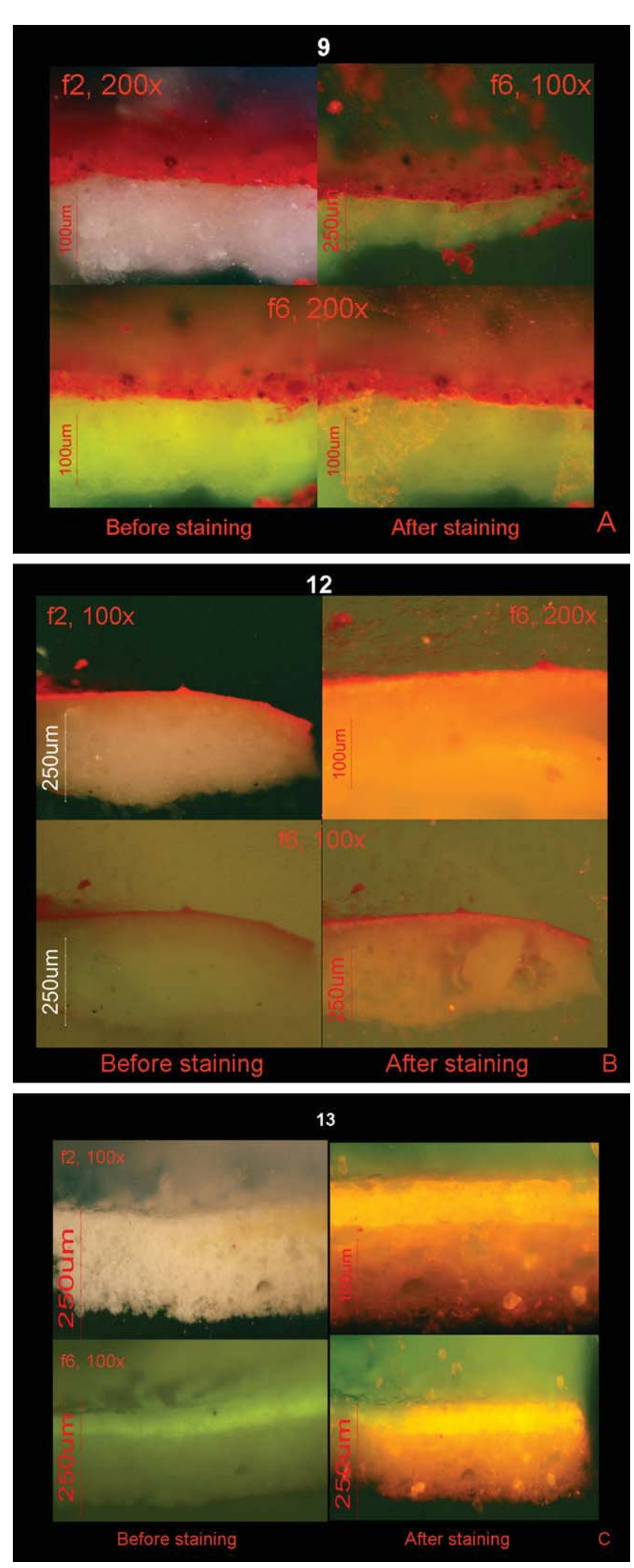

Fig. 4. Visible (f2) and fluorescence (f6) images of three crosssections, before and after staining: (A) 9-alizarin (Al) in whole egg tempera (TEG); (B) 12-vermillion (V) in whole egg tempera (EG); (C) 13Lead white (LW) in egg yolk tempera (EY). [Color figure can be viewed in the online issue, which is available at wileyonlinelibrary.com.]

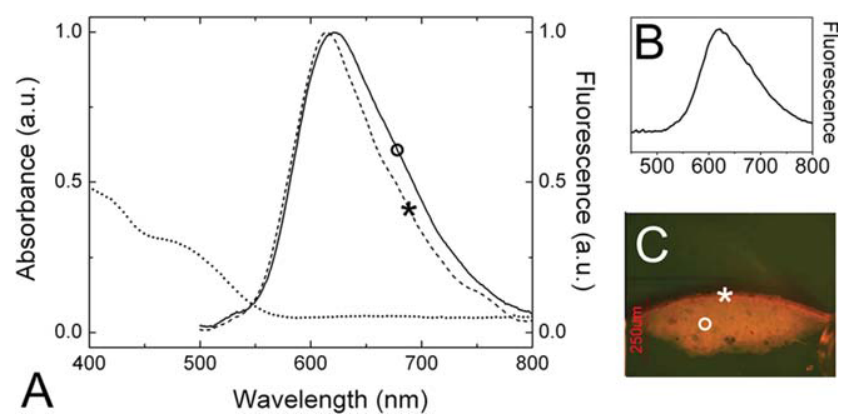

Fig. 5. Fluorescence profiles of the ground (animal glue, solid line) and paint (whole egg, dashed line) layers of cross-section 11 (whole egg and yellow ochre over a ground of animal glue and gesso) after staining with Sypro Ruby: (A) The absorbance of the yellow-ochre (dotted line) does not re-absorb the binder's fluorescence signal, it remains unaltered; (B) the fluorescence profile of the unbound dye; (C) the sample's stratigraphy, where the measurement points are marked with a circle and an asterisk. [Color figure can be viewed in the online issue, which is available at wileyonlinelibrary.com.]

assess the variation of the spectral shape, avoiding non-homogeneous distribution of the binders and of the fluorescence stain amongst different samples. All the acquired profiles showed a broad fluorescence band peak at $620 \mathrm{~nm}$, which is ascribed to Sypro Ruby (see www.invitrogen.com for the optical characterization and Fig. 5B). To obtain significant results, a preliminary selection of samples was carried out with the aim of avoiding paint layers which could potentially affect the fluorescence emission of the binders (i.e., blue or green pigments such as green earth, malachite, or azurite), by re-absorbing a portion of the signal (AA.VV., 2009; Matteini et al., 2009; Sandu et al., 2009) (see Fig. 5A).

Both glue and egg-containing layers showed similar emission profiles regardless of the glue type (animal or fish) or the egg mixture (whole egg, yolk, or white), with the exception of a slight broadening and $\mathrm{a} \sim 5 \mathrm{~nm}$ red-shift observed in the case of the glue (see the example displayed in Fig. 5). The variance observed in the fluorescence profiles may be ascribed to a combination of factors, as literature refers (Deyl et al., 1999; Maeda et al, 1969; Matteini et al, 2009), including a difference in the aminoacid (AA) composition of the protein constituents (i.e., Collagen, Ovalbumin and Phosvitin), the presence of byproducts due to photo-oxidation and of ageing (such as AA derivatives, Maillard products, etc.) and of non-proteinaceous components in the binder (i.e., lipids in egg tempera samples). Variance could also be due to a different structure among the proteins in the formulation used for the sample preparation (i.e., globular, coiled, or mixtures). All of these factors could in principle lead to an interaction of the fluorescent dye with the sample, finally translating in a slight but reproducible spectral fingerprint.

To gain contrast between the qualitative characteristics of the binders, fluorescence spectra were deconvoluted by means of Gaussian curve-fitting analysis. The deconvolution was performed using three spectral components centered at $\sim 615 \mathrm{~nm}$ (band 1), $680 \mathrm{~nm}$ (band 2 ), and $\sim 750 \mathrm{~nm}$ (band 3) wavelengths (see the example of curve fitting displayed in Fig. 6A). A summary of the average integrated areas and amplitudes of the 

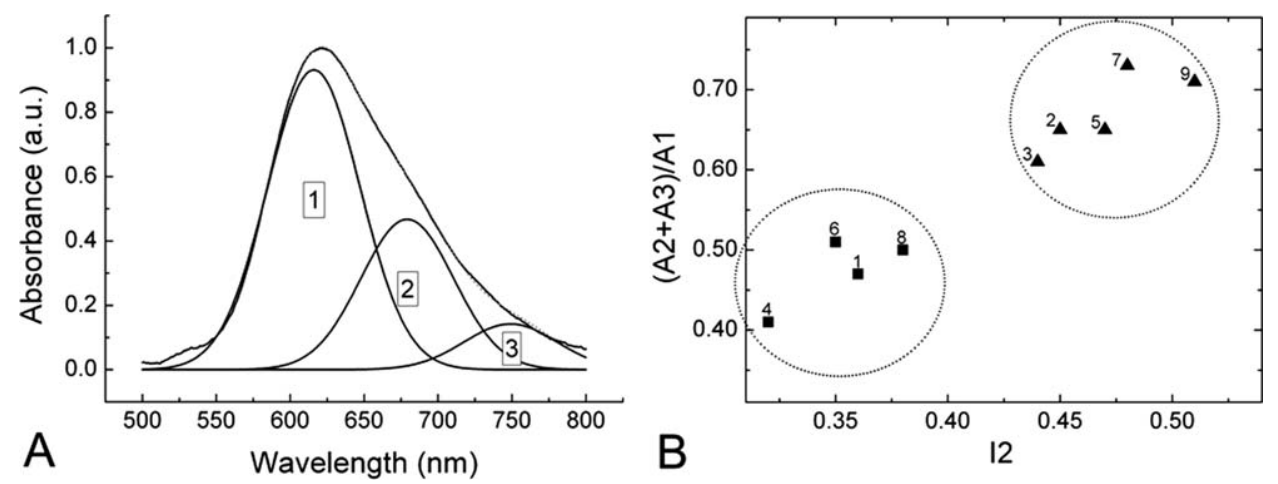

Fig. 6. (A) Example of curve fitting deconvolution of a fluorescence spectrum by three Gaussian bands: band $1 \sim 615 \mathrm{~nm}$, band $2 \sim 680 \mathrm{~nm}$, and band $3 \sim 750 \mathrm{~nm}$; (B) localization of glue- (triangles) and egg- (squares) containing layers by means of the characteristic calculated parameters I2 and $(A 2+$ $A 3) / A 1$ ( $A 1, A 2, A 3$ = integrated areas of the Gaussians constituents, I2 = amplitude of band 2 ).

three components for each sample as obtained by the fitting is reported in Table 3.

A larger variability in both the area and the amplitude of bands 2 and 3 with respect to band 1 was found substantially constant for all the spectra analyzed regardless of the type of binder. Such variability was exploited to highlight spectral differences between glue and egg emissions. Figure $6 \mathrm{~B}$ plots variation of the band 2 intensity (I2) with the $(A 2+A 3) / A 1$ ratio for each sample investigated, where $A 1, A 2$, and $A 3$ are the calculated areas of the Gaussians obtained after deconvolution. The plot points out a differential localization between glue- and egg-containing layers, which can thus be easily distinguished by considering their characteristic deconvoluted fluorescence profile.

\section{CONCLUSIONS}

The results demonstrate that fluorescence imaging and microspectrofluorometry used together create a complementary method for investigation of the location and identification of proteinaceous binders in paintings and polychromes. Using the non-specific fluorescence of the three proteinaceous binders (egg white, egg yolk, and glues), these materials can be located on cross-sections with the aid of the fluorescent dye, and can then be discriminated using the microspectrofluorometric technique.

The results indicate the potential of microspectrofluorometry to discriminate among different protein sources within paint layers when used in conjunction with a dedicated fluorescence dye and suitable deconvolution. A possible limitation of this approach is its lack of reliability for layers which contain colored pigments that partially re-absorb the red fluorescence of the stain. Moreover, discriminating between the fluorescence patterns of whole egg- and egg white-tempera layers appears challenging. However, this protocol offers qualitative insights into the fluorescence properties of a sample over a micron scale, making it a useful analytical tool to discriminate among different proteinaceous materials (such as between egg and glues).

The overall protocol is limited by being time-consuming (for the preparation of the cross-sections, usually requiring from 2 to $12 \mathrm{~h}$, according to the type of embedding resin) and by the fact that the fluorescent stain, even when combined with microspectrofluorometry, is not able to differentiate proteins between terrestrial mammalian animals and fish glues, or between egg white and entire egg.

While other analytical techniques, such as GC-MS or HPLC-MS, offer faster and more efficient protocols of analysis (identification and discrimination) of proteinaceous binders, the advantage of the protocol investigated here is its suitability for mapping the distribution of the binder inside the multi-layered structure of a paint sample in the absence of instrumentation as FTIR mapping. Further experiments should be performed to complement the current methods of fluorescent staining and to investigate other fluorescent probes for non-proteinaceous materials, with immuno-detection using fluorescent labeled antibodies (IFM). Another area which remains to be explored is the applicability of the protocol to complex aged materials from actual paint samples since testing to date has concentrated on fresh samples (8 months to 5 years old).

\section{ACKNOWLEDGMENTS}

The authors acknowledge the extensive editing of the English text by Dr. Leslie Carlyle (Conservation Department of the New University of Lisbon) who kindly supplied samples from the HART project and the kind contribution of Dr. Stepanka Kuckova (Institute of Biotechnology in Prague) for bibliographical indications on the tempera paint recipes.

\section{REFERENCES}

AA.VV. 1962. Fluorescent protein tracing. Nairn RC, editor. Edinburgh, Livingstone. p 280.

AA.VV. 2009. Scientific examination for the investigation of paintings: A handbook for conservators-restorers. Pinna D, Galleotti M, Mazzeo R, editors. Centro Di, Firenze. p 224.

Banks PR, Paquette DM. 1995. Comparison of 3 common amine reactive fluorescent-probes used for conjugation to biomolecules by capillary zone electrophoresis. Bioconjug Chem 6:447-458.

Bottiroli G, Gallone A, Bernacchi E. 1984. Microspectrofluorometric techniques as applied to the analysis of binding media and varnishes in color samples taken from paintings. Perini PL, editor. Montedison Progetto Cultural. Firenze. pp. 168-172.

Bottiroli G, Gallone A, Masala B. 2005. Analisi microspettrofluorimetrica di leganti organici-Microspectrofluorometric analysis of organic binders. Basile G, editor. Bollettino d'Arte. Rome: Ministero per i Beni e le Attività Culturali Volume speciale. pp 83-106. 
Carlyle L. 2001. The artist's assistant. Oil painting instruction manuals and handbooks in Britain 1800-1900 with reference to selected eighteenth-century sources. London: Archetype Publications.

Carlyle L. 2005. De Mayerne Programme HART Report 2002-2005. The historically accurate reconstructions techniques project was hosted by The Netherlands Institute of Cultural Heritage (ICN) and supported by the Netherlands Institute for Atomic and Molecular Physics (FOM-AMOLF) and the Canadian Conservation Institute (CCI). Available from FOM-AMOLF, ICN and CCI.

Cartechini L, Vagnini M, Palmieri M, Pitzurra L, Mello T, Mazurek J, Chiari G. 2010. Immunodetection of proteins in ancient paint media. Acc Chem Res 43:867-876.

Cennini C. 1984. Il libro dell'arte o trattato della pittura/di Cennino Cennini: A cura di Fernando Tempesti,1a ed. Milano: Longanesi.

Dolci L, Sciutto G, Guardigli M, Rizzoli M, Prati S, Mazzeo R, Roda A. 2008. Ultrasensitive chemiluminescent immunochemical identification and localization of protein components in painting crosssections by microscope low-light imaging. Anal Bioanal Chem 392: 29-35.

Doménech-Carbó MT. 2008. Novel analytical methods for characterizing binding media and protective coatings in artworks. Anal Chim Acta 621:109-139.

Deyl Z, Miksik I, Zicha J. 1999. J Chromatogr A 836:161-171.

Florian Mary Lou E. 2007. Protein facts. Fibrous proteins in cultural and natural history artifacts. London: Archetype Publications.

Gay MC. 1976. Application of the staining method to cross-sections in the study of the media of various Italian paintings of the 14th and 15 th centuries. Conservation and restoration of pictorial art. Brommelle, Smith, editors. Conservation Canadian Institute (CCI). pp 78-83.

Gettens RJ, Stout GL. 1966. Painting materials: A short encyclopaedia. New York: Dover Publications.

Holmes KL, Lantz LM. 2001. Protein labeling with fluorescent probes. Methods Cell Biol 63:185-204.

James J, Tas J. 1984. Histochemical protein staining methods. Microscopical Society Handbooks 04, OVP.

Karpowicz A. 1981. Ageing and deterioration of proteinaceous media. SIC 26:153-160.

Leo G, Cartechini L, Pucci P, Sgamellotti A, Marino G, Birolo L. 2009. Proteomic strategies for the identification of proteinaceous binders in paintings. Anal Bioanal Chem 395:2269-2280.

Maeda H, Ishida N, Kawauchi H, Tuzimura K. 1969. Reaction of FITC with proteins and amino acids. J Biochem 5:777-783.

Masschelein Kleiner L. 1992. Liants, vernis et adhesifs anciens. Bruxelles: Institut Royal du Patrimoine Artistique KIK-IRPA.

Matteini P, Camaiti M, Agati G, Baldo MA, Mutoc S, Matteini M. 2009. Discrimination of painting binders subjected to photo-ageing by using microspectrofluorometry coupled with deconvolution analysis. J Cult Heritage 10:198-205.

Messinger JM. 1992. Ultraviolet-fluorescence microscopy of paint cross-sections. JAIC 31:267-274.

Mills JS, White R. 1994. The organic chemistry of museum objects,2nd ed. London: Butterworth-Heinemann.
Nevin A, Comelli D, Valentini G, Anglos D, Burnstock A, Cather S, Cubeddu R. 2007. Time-resolved fluorescence spectroscopy and imaging of proteinaceous binders used in paintings. Anal Bioanal Chem 388:1897-1905.

Phenix A. 1996. The composition and chemistry of eggs and egg tempera. In: Bakkenist T, Hoppenbrouwers R, Dubois H, editors. Early Italian paintings: Techniques and analysis: Symposium. Maastricht, The Netherlands: Limburg Conservation Institute. pp 11-12.

Piqué F. 2006. Il progetto "organic materials in wall paintings." IV Congresso Nazionale IGIIC - Lo Stato dell'Arte, Siena.

Plesters J. 1956. Cross-sections and chemical analysis of paint samples. Stud Conserv 2:110-157.

Rinuy A, Gros L. 1989. Liants dans les peintures anciennes: Methodes d'identification et Etude du vieillissement. Zeitschrift fur Kunstechnologie und Konservierung, Heft 1, Jahrgang 3:9-39.

Sandu ICA, Sandu I, Luca C. 2005. Modern aspects concerning the conservation of the cultural heritage. Vol. II. Authentication and determination of the preservation state of ancient paintings. Iasi: Performantica.

Sandu ICA, Luca C, Sandu I, Vasilache V, Hayashi M. 2008. Authentication of ancient easel-paintings through materials identification from polychrome layers. III. Cross-section analysis and staining tests. Rev Chim Bucharest 8:785-793.

Sandu ICA, Bracci S, Sandu I, Lobefaro M. 2009a. Integrated analytical study for the authentication of five Russian icons (16th-17th centuries). Microsc Res Tech 72:755-765.

Sandu ICA, Roque ACA, Kuckova S, Schaefer S, Carreira R. 2009b. The Biochemistry and Artistic studies: A novel integrated approach to the identification of organic binders in polychrome artifacts, First Issue of the Online Review Estudos de Conservacao e Restauro (ECR). Edited by CITAR, Escola das Artes da Universidade Católica Portuguesa, Porto. pp 39-56.

Schäefer S. 1997. Fluorescent staining techniques for the characterization of binding media within paint cross sections and digital image processing for the quantification of staining results. postprints of the symposium on early Italian painting techniques and analysis. Holland: Maastricht.

Slansky B. 1956. Technika v malirske tvorbe (Technique in Painting Creation. Classical book about painting and restoring materials. Pigmentation, thinners, grounds of paintings and fresco). Prague.

Wang F, Beng Tan W, Zhang Y, Fan X, Wang M. 2006. Luminescent nanomaterials for biological labeling. Nanotechnology 17: R1-R13.

White R. 1984. The characterization of proteinaceous binders in art objects. Natl Gallery Techn Bull 5-14.

Wolbers R, Sterman N, Stavroudis C. 1990. Microscopy-Interpreting stains. Notes for workshop on new methods in the cleaning of paintings. Getty Conservation Institute (GCI), GCI58

Wolbers R. 2000. Cleaning painted surfaces. Aqueous methods. London: Archetype Publications.

Wolbers R, Landrey G. 1987. The use of direct reactive fluorescent dyes for the characterization of binding media in cross sectional examinations. AIC preprints. 15th Annual Meeting. Washington DC: American Institute for Conservation. pp 168-202. 